\title{
Naming and verbal learning in adults with Alzheimer's disease, mild cognitive impairment and in healthy aging, with low educational levels
}

\author{
Nomeação e aprendizagem verbal na doença de Alzheimer, no comprometimento \\ cognitivo leve e no envelhecimento sadio com baixa escolaridade \\ Lilian Cristine Hübner, ${ }^{1,2}$, Fernanda Loureiro ${ }^{3}$, Bruna Tessaro', Ellen Cristina Gerner Siqueira', Gislaine \\ Machado Jerônimo', Irênio Gomes ${ }^{3}$, Lucas Porcello Schilling ${ }^{4}$
}

\begin{abstract}
Language assessment seems to be an effective tool to differentiate healthy and cognitively impaired aging groups. This article discusses the impact of educational level on a naming task, on a verbal learning with semantic cues task and on the MMSE in healthy aging adults at three educational levels (very low, low and high) as well as comparing two clinical groups of very low (0-3 years) and low education (4-7 years) patients with Alzheimer's disease (AD) and mild cognitive impairment (MCl) with healthy controls. The participants comprised 101 healthy controls, 17 patients with $\mathrm{MCl}$ and 19 with $\mathrm{AD}$. Comparisons between the healthy groups showed an education effect on the MMSE, but not on naming and verbal learning. However, the clinical groups were differentiated in both the naming and verbal learning assessment. The results support the assumption that the verbal learning with semantic cues task is a valid tool to diagnose $\mathrm{MCl}$ and $\mathrm{AD}$ patients, with no influence from education.
\end{abstract}

Keywords: verbal learning; Alzheimer's disease; cognitive disfunction.

\section{RESUMO}

A linguagem tem se mostrado uma ferramenta eficiente para diferenciar grupos de idosos saudáveis dos com deficiências cognitivas. 0 artigo objetiva discutir o impacto do nível educacional na nomeação, na aprendizagem verbal (AV) com pistas semânticas e no MEEM no envelhecimento saudável em três níveis de escolaridade (muito baixa: 0-3 anos, baixa: 4-7 anos e alta: >8 anos) e em dois grupos clínicos de escolaridade muito baixa e baixa (Doença de Alzheimer - DA - e Comprometimento Cognitivo Leve - CCL), comparados a controles saudáveis. Participaram 101 controles, 17 CCL e 19 DA. Comparações entre grupos saudáveis demonstraram um efeito da escolaridade no MEEM, mas não nas tarefas de nomeação e de AV. Considerando as comparações entre os grupos clínicos, tanto a nomeação quanto a AV os diferenciaram. Os resultados corroboram a pressuposição de que a tarefa de AV com pistas semânticas é válida para diagnosticar CCL e DA, não sendo influenciada pela escolaridade.

Palavras-chave: aprendizagem verbal; doença de Alzheimer, disfunção cognitiva.

A growing increase in the aging population has been observed over the past decades. Between 2015 and 2050, the number of older people living in higher income countries is predicted to increase by only $56 \%$, compared to $138 \%$ in upper middle income countries, $185 \%$ in lower middle income countries, and by $239 \%$ (more than triple the increase) in low income countries ${ }^{1}$.

Approximately 46.8 million people worldwide were living with dementia in 2015. This number will almost double every 20 years $^{1}$. Education appears to play a crucial role in the increase of dementia, and language has been indicated as an effective way to assess cognitive decline.

The aim of this article is to compare the performance of healthy and clinical aging groups in a naming and a verbal learning task with semantic cues, as well as in the Mini Mental State Examination (MMSE), considering the impact of their educational level. More specifically, the objectives are twofold: firstly, to analyze performance in naming, verbal

${ }^{1}$ Pontifícia Universidade Católica do Rio Grande do Sul, Departamento de Linguística, Porto Alegre RS, Brasil;

${ }^{2}$ Conselho Nacional de Desenvolvimento Científico e Tecnológico (CNPq)

${ }^{3}$ Pontifícia Universidade Católica do Rio Grande do Sul, Instituto de Geriatria e Gerontologia, Porto Alegre RS, Brasil;

${ }^{4}$ Instituto do Cérebro, Porto Alegre RS, Brasil.

Correspondence: Lilian Cristine Hübner; Departamento de Linguística da PUCRS; Av Ipiranga, 6681; $90619-900$ Porto Alegre RS, Brasil; E-mail:

lilian.hubner@pucrs.br/lilian.c.hubner@gmail.com

Conflict of interest: There is no conflict of interest to declare.

Received 15 May 2017; Received in final form 19 October 2017; Accepted 21 November 2017. 
learning and the MMSE in healthy aging groups distributed over three different educational levels (very low, low and high level), and secondly, to analyze performance in the same tasks in low and very low educational level groups diagnosed with mild cognitive impairment (MCI) and Alzheimer's disease $(\mathrm{AD})$, compared to a healthy aging group.

\section{The impact of educational level in the assessment of naming and verbal learning}

Although education is a very important factor when evaluating cognitive decline, most of the available evidence on linguistic and other cognitive abilities has been assessed in highly-educated $\mathrm{AD}$ and $\mathrm{MCI}$ participants.

Connor et al. ${ }^{2}$ investigated the relationship between naming performance in the Boston Naming Test, age, education and gender. Their results showed that less educated women had the poorest performance in the Boston Naming Test, though the authors claim that such results may not be universal. Welch et al. ${ }^{3}$ participants with 12 or more years of education had better performances in naming compared with participants with less than 12 years of education. However, this difference was only found when elderly groups were compared, whereas, in younger groups, the education effect was not found. Ashaie and Obler ${ }^{4}$ administered a culturally-adapted naming task to a rural low education Indian cohort and found no education effect with age. However, when comparing illiterates with educated participants, they found educated individuals at an advantage in the naming task.

Low levels of schooling may obscure the diagnosis of cognitive decline, which shows the necessity of task adaptation to this population ${ }^{5,6}$.

\section{Naming and verbal learning in cognitive impairment}

This section presents theoretical and experimental data on naming and verbal learning in $\mathrm{MCI}$ and $\mathrm{AD}$.

\section{Naming and semantic memory}

The main concern in the elderly is to depict when an alteration is considered normal within a healthy aging framework and when it signals the onset of dementia. One of the tasks aimed at establishing this cut-off is word retrieval, which is frequently best assessed through naming tasks ${ }^{7}$. Several theories have emerged to explain word retrieval processes in the brain. One of them is the Node Structure Theory ${ }^{8}$, which posits that there is a network of interconnected nodes hierarchically organized into a semantic, a phonological and an orthographic system. In picture naming, the pictorial stimulus first activates semantic nodes, which then transmit excitation to the lexical representations of the word; then the phonological representations are activated to produce the word. There are three factors that influence a transmission deficit between the phonological, lexical and semantic levels: the frequency with which a word is used, recency of use (the amount of time passed since the word had last been used), and aging 9 In healthy aging, a tip-of-the-tongue state is quite common, occurring when the connections to the phonological system are weakened, and providing a phonological tip, in general, solves the problem ${ }^{9}$. However, in dementia, semantic errors are more common than phonological errors, suggesting a degradation of the semantic system itself or an impaired access to it.

Silagi et al. ${ }^{10}$ confirmed an increase in the number of errors in naming tasks as $\mathrm{AD}$ progresses. The most common types of errors in the naming tasks were semantic paraphasias and non-responses (classified as pure anomia), which seemed to be related to loss of semantic information.

A criticism of many of the studies on semantic memory in $\mathrm{MCI}$ and $\mathrm{AD}$ is over task design, which has not always observed psycholinguistic criteria on stimuli construction, disregarding variables such as categories (words that represent possible examples of a concept, for instance, "birds"), polysemy (words with more than one meaning, for instance, "fan", in English), prototypicality (the level at which a word is representative of its category; for instance, a canary is more prototypical for the category of "bird" than a penguin), age of acquisition (the age at which a word has been acquired), familiarity (the level at which entities in a particular category resemble one another in a number of ways), frequency (the frequency of which a word is used in communication, reading or writing material), living versus nonliving (elements which refer to animate items or manufactured/man-made items), among other variables. Moreover, there is a lack of validated instruments to assess language and other cognitive constructs in low educated individuals, which has been addressed, for instance, by Brazilian research developed by Mansur et al. ${ }^{11}$, and Miotto et al. ${ }^{12}$.

\section{Verbal learning and episodic memory}

Impairment in episodic memory is a symptom most commonly observed in MCI with an amnestic etiology, and in $\mathrm{AD}$. The Free and Cued Selective Reminding Test (FCSRT) ${ }^{13}$ is one of the tests most adapted to evaluate episodic memory and is recommended by the International Working Group ${ }^{14}$. It evaluates the ability to learn words that are presented with a semantic cue to control for memory encoding. The FCSRT has both pictorial and word versions, with the pictorial version suitable for populations with low socioeconomic status, who are generally illiterate or have a low literacy. A review of studies administering versions of the selective reminding task, including its use in Brazilian studies, can be found in Bordignon et al. ${ }^{15}$.

Auriacombe et al. ${ }^{16}$ assessed the validity of the FCSRT in predicting dementia two and five years after an initial evaluation in a population-based cohort over the age of 65 participating in the French Three-City (3C) study. They concluded that high FCSRT scores were useful to rule out dementia. Dubois et al. ${ }^{17}$ considered free and cued recall measures as 
valid clinical markers of the clinical phenotype of $\mathrm{AD}$, to be adopted, among other scales, to distinguish between preclinical and prodromal AD. Similarly, Teichmann et al. ${ }^{18}$ postulated that the FCSRT appeared to be a sensitive tool for diagnosing typical $\mathrm{AD}$ among other neurodegenerative diseases with a sensitivity of $100 \%$ and a specificity of $75 \%$. The authors argued that the FCSRT reliability could minimize false non- $\mathrm{AD}$ diagnoses in the spectrum of atypical $\mathrm{AD}$ biomarker-positive degenerative diseases.

Lemos et al. ${ }^{19}$ administered the FCSRT to three groups: control group (C) ( $\mathrm{n}=101)$, MCI group $(\mathrm{n}=100)$, and AD group $(\mathrm{n}=70)$. The mean age and educational level median were, respectively, $(\mathrm{M}=70.22$; 4 [4.11] $)$, $(\mathrm{MCI}=71.08 ; 4[4.9])$ and $(\mathrm{AD}=72.63 ; 4[4.11])$. They concluded that the FCSRT was a very useful tool to identify memory impairment on the $\mathrm{AD}$ spectrum and to differentiate between $\mathrm{AD}$ and $\mathrm{MCI}$ groups, compared with controls. Both the immediate and the delayed recalls demonstrated a significant impairment in the two clinical groups. None of the demographic characteristics, including education, showed a significant effect on the results.

Grober et al. ${ }^{20}$ compared participants' performances in the FCSRT and in the MMSE, to identify mild dementia among Spanish-speaking Latino participants. The participants were 112 elderly, 24 of whom were diagnosed with dementia, with a mean of 7.36 years of education. The FCSRT, especially its free recall component, showed higher sensitivity and specificity than the MMSE in detecting mild dementia. For participants without dementia, the MMSE scores were associated with years of education, while free recall scores were not. These results suggested that the FCSRT could be considered an effective tool for dementia screening in individuals with varying levels of education.

Aiming at verifying whether education could have an impact in healthy populations, we compared the performances of three healthy groups in a naming and a verbal learning task, adapted from the FCSRT. Moreover, we aimed to investigate the influence of low educational levels by comparing the performances of healthy and cognitively impaired populations ( $\mathrm{AD}$ and $\mathrm{MCI})$ in these same tasks.

\section{METHOD}

The study was approved by the Ethics Research Committee at the Pontifical Catholic University of Rio Grande do Sul, in Porto Alegre, Brazil, protocol number 21006913.0.0000.5336, following Resolution 466/12.

\section{Participants}

All participants gave formal consent before the testing, and received no financial compensation for their participation. The study included 137 individuals (101 healthy, $17 \mathrm{MCI}, 19 \mathrm{AD}$ ).

The healthy participants were classified into three educational groups (Table 1 shows their sociodemographic characteristics). Healthy controls with low education were recruited by community health agents and interviewed and tested by the research group, while the healthy highly educated group was selected from meeting groups and community centers for the elderly.

Clinical patients were receiving treatment at a neurological clinic in a public hospital in the metropolitan area of Porto Alegre, Brazil. All the participants had a low education level (Table 1). In the very low educational level groups (healthy and clinical), a small number of illiterate elderly were included, as the tasks did not require reading ability. Moreover, individuals with zero to three years of formal education may present as functionally illiterate or, on the contrary, they may have developed reading/writing abilities from self-training.

Exclusion criteria for healthy and clinical groups were the self-reporting of a previous stroke, brain tumors or psychiatric disorders such as bipolar disorder or schizophrenia, current or past alcohol or drug abuse history, or under-corrected auditory or vision difficulties. The $\mathrm{AD}$ patients with a score equal to or higher than 3 in the Clinical Dementia Rating were excluded.

Table 1. Descriptive information of healthy and clinical participants.

\begin{tabular}{|c|c|c|c|c|c|c|c|}
\hline \multirow{2}{*}{ Groups } & \multirow{2}{*}{ Years of schooling } & \multicolumn{3}{|c|}{$\mathrm{N}$} & \multicolumn{3}{|c|}{ Age } \\
\hline & & Male & Female & $\mathrm{p}$ & Mean & SD & $p$ \\
\hline \multicolumn{8}{|l|}{ Healthy } \\
\hline Very low education & $0-3$ & 3 & 11 & 0.275 & $72.1^{\mathrm{a}}$ & 6.3 & 0.018 \\
\hline Low education & $4-7$ & 10 & 24 & & $71.0^{a}$ & 6.3 & \\
\hline High education & $>8$ & 8 & 45 & & $68.1^{b}$ & 5.2 & \\
\hline \multicolumn{8}{|l|}{$\mathrm{MCl}$} \\
\hline Very low education & $0-3$ & 2 & 6 & 0.487 & 72.4 & 4.0 & 0.993 \\
\hline Low education & $4-7$ & 2 & 7 & & 70.6 & 5.9 & \\
\hline \multicolumn{8}{|l|}{$\mathrm{AD}$} \\
\hline Very low education & $0-3$ & 4 & 5 & 0.902 & 72.0 & 10.0 & 0.500 \\
\hline Low education & $4-7$ & 3 & 7 & & 73.5 & 6.3 & \\
\hline
\end{tabular}

$\mathrm{MCl}$ : mild cognitive impairment;AD:Alzheimer's disease;SD: standard deviation; a,b, Same letters indicate there is no statistical difference between comparisons, while different letters indicate statistically significant differences between comparisons. The comparison includes the healthy, MCI and AD groups with same level of education. 


\section{Instruments and procedures for data collection}

The psychiatric evaluation was conducted by the administration of the Geriatric Depression Scale ${ }^{21}$ and the Mini International Neuropsychiatric Interview PLUS ${ }^{22}$ - version 5, complemented by the criteria of the Diagnostic and Statistical Manual of Mental Disorders - DSM-IV-TR. The criteria recommended by the National Institute on Aging-Alzheimer's Association ${ }^{23}$ were used to clinically diagnose $\mathrm{MCI}$ and $\mathrm{AD}$, together with the anamnesis including physical examination and questions for the participant and/or to the caregiver or relative about functional capacity. The MMSE scores ${ }^{24}$ (from 0 to 30 ) were taken into consideration as indicators of objective cognitive impairment, using the cut-off points for the Brazilian population, as proposed by Chaves and Izquierdo ${ }^{25}$. Thus, the cut-off points were 17 for the illiterate or functionally illiterate and 22 for those with more than four years of education. As for the clinical groups, the healthy adults were tested with the MMSE, Geriatric Depression Scale and questions about functional capacity, and were invited to participate when they reached adequate performances on these tests.

\section{Naming task}

The task consisted of naming 60 line drawings, including 30 living and 30 nonliving concepts, balanced according to word frequency. The final answer given by the participant was registered.

\section{Verbal learning task}

A modified version, adapted to Brazilian Portuguese, of the FCSRT ${ }^{26}$ was administered to assess episodic memory and verbal learning ability. Scores of the free recall and of the total recall (sum of immediate and delayed free and cued recalls) were analyzed in this study.

These two tasks are subtests of a language evaluation battery (Bateria de Avaliação da Linguagem no Envelhecimento, Battery of Language Assessment in Aging - accepted, in preparation $)^{27}$, linguistically and socio-culturally adapted to the Brazilian population, adjusted for administration to low socioeconomic status and illiterate cohorts.

\section{Data analysis}

Data were analyzed with the statistical package SPSS 17. The description of the data was done through absolute and relative frequencies, means and standard deviations. Comparisons of demographic characteristics between the groups were done using Pearson's chi-squared test. An ANOVA test was used to compare the means of the cognitive evaluation scores of the healthy to the very low, low and high education groups. The intergroup analyses comparing the three healthy groups were adjusted for age using an ANCOVA test, as the mean age of the highly educated healthy group was higher than the means of the other two education level groups. An ANOVA test was also used to compare the means of the cognitive evaluation scores of the very low educated and low educated in healthy, MCI and AD groups. A post-hoc analysis was made using the Tukey Test. The significance level considered was $\mathrm{p}<0.05$.

\section{RESULTS}

The sociodemographic characteristics of the groups are presented in Table 1.

Considering the healthy groups' performances in the MMSE, the very low educational level group $(24.4 \pm 3.8)$ had significantly lower scores than the low $(26.6 \pm 3.2)$ and high educational groups $(28.4 \pm 1.7)(\mathrm{p}<0.001)$ (Table 2). Regarding the two other language tasks, the naming task showed statistically significant differences among groups: the very low educational level group $(51.4 \pm 6.0)(\mathrm{p}<0.002)$ differed from the low educated (53.3 \pm 4.6$)$ and highly educated (55.3 \pm 2.5$)$. However, when an ANCOVA was performed to adjust for the age difference between groups, as the mean age of the highly-educated group was higher than the two other healthy groups, no differences were seen between groups in the naming task ( $\mathrm{p}<$ 0.121). Regarding the FCSRT task, no statistically significant differences were found in the comparison among the healthy groups' performances in the "total" scores ( $\mathrm{p}<0.482)$.

Regarding the clinical groups, significant differences were found in the comparisons between very low, and low education $(\mathrm{p}<0.001)$ in the MMSE (Tables 3 and 4). Of note, the mean obtained by the very low educated healthy group (24.4 \pm 3.8$)$, MCI (19.3 \pm 5.1$)$ and AD (16.6 \pm 2.4$)$ was very low. Controls showed significantly higher scores (26.6 \pm 3.2$)$, followed by the MCI group (23.1 \pm 3.5$)$ and the AD group (19.5 \pm 2.6$)$ (Table 4).

Table 2. Healthy participants' performance $(N=101)$ : mean results and SD.

\begin{tabular}{|c|c|c|c|c|c|}
\hline \multirow{3}{*}{ Task } & \multicolumn{3}{|c|}{ Educational group } & \multirow{3}{*}{$p^{*}$} & \multirow{3}{*}{$p^{* *}$} \\
\hline & Very Low & Low & High & & \\
\hline & $0-3$ & $4-7$ & $>8$ & & \\
\hline MMSE & $24.5(3.8)^{a}$ & $26.6(3.2)^{b}$ & $28.4(1.7)^{\mathrm{C}}$ & $<0.001$ & 0.006 \\
\hline FCSRT - Identification & $16.0(0.0)$ & $16.0(0.0)$ & $16.0(0.0)$ & - & - \\
\hline FCSRT - Total of free recall & $29.4(6.3)$ & $31.5(5.8)$ & $33.8(6.0)$ & 0.031 & 0.126 \\
\hline FCSRT - Total sum & $47.1(1.6)$ & $47.4(1.2)$ & $47.5(0.9)$ & 0.482 & 0.306 \\
\hline Naming & $51.4(6.0)^{a}$ & $53.3(4.6)^{b}$ & $55.3(2.5)^{c}$ & 0.002 & 0.121 \\
\hline
\end{tabular}

SD: standard deviation; MMSE: Mini Mental State Examination; FCSRT: Free and Cued Selective Reminding Test; a,b,c: In each task values marked with the different letter had statistically significant differences between them. *ANOVA; **ANCOVA. 
Table 3. Very low educational group's performance (0-3): mean results and SD.

\begin{tabular}{|c|c|c|c|c|}
\hline \multirow{3}{*}{ Task } & \multicolumn{3}{|c|}{ Very low educational group } & \multirow{3}{*}{$\mathrm{p}$} \\
\hline & Healthy & $\mathrm{MCl}$ & $A D$ & \\
\hline & $N=14$ & $N=8$ & $N=9$ & \\
\hline MMSE & $24.4(3,8)^{a}$ & $19.3(5.1)^{b}$ & $16.6(2.4)^{\mathrm{c}}$ & $<0.001$ \\
\hline FCSRT - Total of free recall & $29.4(6.3)^{a}$ & $18.6(9.1)^{b}$ & $15.2(5.1)^{c}$ & $<0.001$ \\
\hline FCSRT - Total sum & $47.1(1.6)^{a}$ & $39.0(7.2)^{b}$ & $33.2(9.6)^{b}$ & $<0.001$ \\
\hline Naming & $51.4(6.0)^{a}$ & $45.3(7.6)^{b}$ & $39.7(4.0)^{c}$ & $<0.001$ \\
\hline
\end{tabular}

MCl: mild cognitive impairment; AD: Alzheimer's disease; SD: standard deviation; FCSRT: Free and Cued Selective Reminding Test; a,b,c: In each task values marked with the same letter had no statistically significant differences between them.

Table 4. Low educational group's performance (4-7): mean's results and SD.

\begin{tabular}{|c|c|c|c|c|}
\hline \multirow{3}{*}{ Task } & \multicolumn{3}{|c|}{ Low educational group } & \multirow{3}{*}{$\mathrm{p}$} \\
\hline & Healthy & $\mathrm{MCl}$ & $A D$ & \\
\hline & $N=34$ & $\mathrm{~N}=9$ & $\mathrm{~N}=10$ & \\
\hline MMSE & $26.6(3.2)^{a}$ & $23.1(3.5)^{b}$ & $19.5(2.6)^{c}$ & $<0.001$ \\
\hline FCSRT - Total of free recall & $31.5(5.8)^{a}$ & $18.2(8.2)^{b}$ & $10.5(6.4)^{c}$ & $<0.001$ \\
\hline FCSRT - Total sum & $47.4(1.2)^{a}$ & $41.6(8.2)^{b}$ & $25.7(8.2)^{\circ}$ & $<0.001$ \\
\hline Naming & $53.3(4.6)^{a}$ & $52.2(4.7)^{b}$ & $44.1(6.5)^{c}$ & $<0.001$ \\
\hline
\end{tabular}

Considering each group's performance in the naming task, the comparison of very low educational groups also showed statistical differences between the two clinical groups $(\mathrm{MCI}=45.3 \pm 7.6$ and $\mathrm{AD}=39.7 \pm 4.0)$, and both groups differed from the healthy controls $(51.4 \pm 6.0)(p<0.001)$. Moreover, the comparison of low educational groups revealed that healthy controls $(53.3 \pm 4.6)$ differed from the MCI group $(52.2 \pm 4.7)$ and $\mathrm{AD}$ group $(44.1 \pm 6.5)(\mathrm{p}<0.001)$.

Significant differences were observed in the comparisons of the two levels of education in the FCSRT. In the comparison among very low educational groups, considering the scores of total recall (FCSRT - total sum), the healthy control group (47.1 \pm 1.6$)$ significantly differed from the two clinical groups $(\mathrm{p}<0.001), \mathrm{MCI}(39.0 \pm 7.2)$ and $\mathrm{AD}(33.2 \pm 9.6)$. Yet the comparison among low educational groups revealed significant differences in the performance of all groups $(\mathrm{p}<0.001)$ : controls (47.4 \pm 1.2$)$, MCI (41.6 \pm 8.2$)$ and $\mathrm{AD}(25.7 \pm 8.2)$.

\section{DISCUSSION}

The data comparing the three healthy groups in the naming ability showed no significant differences between the different educational level groups. When stimuli are adapted to a lower educated population, as it was the case in our study, healthy participants with very low education level may perform well. However, this result, analyzed in a small sample, should be considered with caution. There is clearly a need for further studies on the interplay between age, low education and illiteracy, adopting culturally-adapted stimuli in naming tasks, as inconsistent results have been found and no conclusive data has been reached so far, probably because of the discrepancies between task designs and the populations investigated $^{3,4}$. The naming task distinguished between the healthy and the two clinical groups in low education, corroborating studies previously discussed in this article ${ }^{7,10}$. Thus, naming ability has shown to be an important window for indicating when an alteration in semantic memory signals the onset of cognitive decline or dementia, demonstrated by a decreasing performance in $\mathrm{AD}^{10}$.

The verbal learning task was shown not to be biased by educational level in the healthy groups. The majority of the screening and cognitive tests are affected by education, an aspect that demands adapted cut-offs depending on the educational level. The absence of a significant effect of education on this verbal learning task with semantic cues makes it possible to consider this test as a very useful tool for differentiating $\mathrm{MCI}$ and $\mathrm{AD}$, without the need for adjustment for different educational levels. This result is in line with that found by Lemos et al. ${ }^{19}$. Moreover, in the clinical groups, the results of our study suggest that neither MCI nor $\mathrm{AD}$ participants benefited from the oral presentation of semantic cues provided by the examiner whenever they were unable to retrieve a word, which could suggest unsuccessful encoding, rather than a problem specifically at the retrieving level, since retrieval should benefit from the semantic cues provided by the examiner following successful encoding ${ }^{19,20}$. Difficulties with episodic memory, that is, difficulties with learning and retaining new knowledge, are observed in MCI with an amnestic etiology, which usually progresses to $\mathrm{AD}$. Taken together, the results showed that the FCSRT efficiently evaluates verbal learning skills and has shown to be a useful test for characterizing episodic memory deficits in MCI and $\mathrm{AD}^{19}$, as seen in Tables 3 and 4 . Our data showed that the task was able to distinguish not only the clinical groups from the healthy control group, but also to distinguish the MCI and 
$\mathrm{AD}$ groups from each other, while the educational level did not influence the performance in this task.

The results of the administration of the MMSE were able to distinguish low education healthy participants from equally low education clinical populations, corroborating other studies ${ }^{6,28}$. Moreover, the sensitivity of the MMSE was higher in low education groups than in very low ones. It is important to consider a very low cut-off point in both clinical and healthy groups, due to the high sensitivity of the MMSE to the impact of education ${ }^{29}$. Similarly, attention should be given to the use of specific norms according to age in tests pointing to differences relating to educational level when assessing healthy controls.

In conclusion, in this study we aimed to compare intertwined linguistic and memory performances of healthy elderly participants, divided into three education level groups (very low, low and high), as well as compare the linguistic performance of cognitively impaired populations (MCI and $\mathrm{AD}$ ) to that of a healthy group. A limitation of the study was the small number of participants per group, which does not allow generalizations to be made from the data. Moreover, further studies should specifically study naming and verbal learning in representative illiterate groups, as illiteracy may play a role in these and in other linguistic tasks, as pointed out by Leite et al..$^{30}$ in their study on the adaptation of the Boston Naming Test. Despite our limited number of participants, our results appear to corroborate previous literature by indicating that the MMSE, naming tasks and verbal learning tasks are ways of distinguishing between clinical and control groups. Furthermore, the results confirm the sensitive role of the MMSE in distinguishing among varying educational level groups in the healthy aging population. On the other hand, the FCSRT was able to differentiate between the two clinical groups, corroborating its valuable contribution in assessing clinical populations with no educational level interference. The growing refinement of language tasks and batteries, especially those designed for low educational level populations, may provide support for early diagnosis of cognitive impairment.

\section{References}

1. Prince M, Wimo A, Guerchet M, Ali G, Wu Y, Prina M. World Alzheimer Report 2015, The Global Impact of Dementia: an analysis of prevalence, incidence, cost and trends. London: Alzheimer's Disease International; 2015.

2. Connor LT, Spiro A 3rd, Obler LK, Albert ML. Change in object naming ability during adulthood. J Gerontol B Psychol Sci Soc Sci. 2004 Sep;59(5):203-9. https://doi.org/10.1093/geronb/59.5.P203

3. Welch LW, Doineau D, Johnson S, King D. Educational and gender normative data for the Boston Naming Test in a group of older adults. Brain Lang. 1996 May;53(2):260-6. https://doi.org/10.1006/brln.1996.0047

4. Ashaie S, Obler L. Effect of age, education, and bilingualism on confrontation naming in older illiterate and low-educated populations. Behav Neurol. 2014;2014:970520. https://doi.org/10.1155/2014/970520

5. Passos VMA, Giatti L, Bensenor I, Tiemeier H, Ikram MA, Figueiredo $\mathrm{RC}$ et al. Education plays a greater role than age in cognitive test performance among participants of the Brazilian Longitudinal Study of Adult Health (ELSA-Brasil). BMC Neurol. 2015 Oct;15(1):191. https://doi.org/10.1186/s12883-015-0454-6

6. Radanovic M, Diniz BS, Mirandez RM, Novaretti TM, Flacks MK, Yassuda MS et al. Verbal fluency in the detection of mild cognitive impairment and Alzheimer's disease among Brazilian Portuguese speakers: the influence of education. Int Psychogeriatr. 2009 Dec;21(6):1081-7. https://doi.org/10.1017/\$1041610209990639

7. Reilly J, Peelle JE, Antonucci SM, Grossman M. Anomia as a marker of distinct semantic memory impairments in Alzheimer's disease and semantic dementia. Neuropsychology. $2011 \mathrm{Jul} ; 25(4): 413-26$. https://doi.org/10.1037/a0022738

8. MacKay DG. The organization of perception and action: a theory for language and other cognitive skills. New York: Springer; 1987.

9. Burke DM, Mackay DG, Worthley JS, Wade E. On the tip of the tongue: what causes word finding failures in young and older adults? J Mem Lang. 1991;30(5):542-79. https://doi.org/10.1016/0749-596X(91)90026-G

10. Silagi ML, Bertolucci PH, Ortiz KZ. Naming ability in patients with mild to moderate Alzheimer's disease: what changes occur with the evolution of the disease? Clinics (Sao Paulo). 2015 Jun;70(6):423-8. https://doi.org/10.6061/clinics/2015(06)07

11. Mansur LL, Radanovic M, Araújo GC, Taquemori LY, Greco LL. Boston naming test: performance of Brazilian population from São Paulo. Pro Fono. 2006 Jan-Apr;18(1):13-20. https://doi.org/10.1590/S0104-56872006000100003

12. Miotto EC, Sato J, Lucia MC, Camargo CH, Scaff M. Development of an adapted version of the Boston Naming Test for Portuguese speakers. Rev Bras Psiquiatr. 2010 Sep;32(3):279-82. https://doi.org/10.1590/S1516-44462010005000006

13. Grober E, Buschke H, Crystal H, Bang S, Dresner R. Screening for dementia by memory testing. Neurology. 1988 Jun;38(6):900-3. https://doi.org/10.1212/WNL.38.6.900

14. Dubois B, Feldman HH, Jacova C, Hampel H, Molinuevo JL, Blennow $K$ et al. Advancing research diagnostic criteria for Alzheimer's disease: the IWG-2 criteria. Lancet Neurol. 2014 Jun;13(6):614-29. https://doi.org/10.1016/S1474-4422(14)70090-0

15. Bordignon S, Zibetti MR,Trentini CM. [Assessing Memory and learning using the selective reminding procedure: a survey of Brazilian studies]. Psic Teor Pesq. 2016:32(2):e32221. Portuguese. https://doi.org/10.1590/0102-3772e32221

16. Auriacombe S, Helmer C, Amieva H, Berr C, Dubois B, Dartigues JF Validity of the free and cued selective reminding test in predicting dementia: the 3C study. Neurology. 2010 Jun;74(22):1760-7. https://doi.org/10.1212/WNL.0b013e3181df0959

17. Dubois B, Hampel H, Feldman HH, Scheltens P, Aisen P, Andrieu $S$ et al. Preclinical Alzheimer's disease : definition, natural history, and diagnostic criteria. Alzheimers Dement.2016 Mar;12(3):292-323. https://doi.org/10.1016/j.jalz.2016.02.002

18. Teichmann M, Epelbaum S, Samri D, Nogueira ML, Michon A, Hampel $\mathrm{H}$ et al. Free and Cued Selective Reminding Test: accuracy for Alzheimer's and neurodegenerative disease differential diagnosis : A large-scale biomarker-characterized monocenter cohort study (ClinAD). Alzheimers Dement. 2017 Feb;13(8):913-23. https://doi.org/10.1016/j.jalz.2016.12.014 
19. Lemos R, Simões M, Santiago B, Santana I. The free and cued selective reminding test: validation for mild cognitive impairment and Alzheimer's disease. J Neuropsychol. 2014 Sep;9(2):242-57. https://doi.org/10.1111/jnp.12048

20. Grober E, Ehrlich AR, Troche Y, Hahn S, Lipton RB. Screening older Latinos for dementia in the primary care setting. J Int Neuropsychol Soc. 2014 Sep;20(8):848-55. https://doi.org/10.1017/\$1355617714000708

21. Almeida OP, Almeida SA. [Reliability of the Brazilian version of the Geriatric Depression Scale (GDS) short form]. Arq Neuropsiquiatr. 1999 Jun;57(2B):421-6. Portuguese. https://doi.org/10.1590/S0004-282X1999000300013

22. Amorim P. [Mini International Neuropsychiatric Interview (MINI): validation of a short structured diagnostic psychiatric interview]. Rev Bras Psiquiatr. 2000 Sep;22(3):106-15. Portuguese. https://doi.org/10.1590/S1516-44462000000300003.

23. McKhann GM, Knopman DS, Chertkow H, Hyman BT, Jack CR Jr, Kawas $\mathrm{CH}$ et al. The diagnosis of dementia due to Alzheimer's disease: recommendations from the National Institute on Aging-Alzheimer's Association workgroups on diagnostic guidelines for Alzheimer's disease. Alzheimers Dement. 2011 May;7(3):263-9. https://doi.org/10.1016/j.jalz.2011.03.005

24. Folstein MF, Folstein SE, McHugh PR. "Mini-mental state". a practical method for grading the cognitive state of patients for the clinician. J Psychiatr Res. 1975 Nov;12(3):189-98. https://doi.org/10.1016/0022-3956(75)90026-6
25. Chaves ML, Izquierdo I. Differential diagnosis between dementia and depression: a study of efficiency increment. Acta Neurol Scand. 1992 Jun;85(6):378-82. https://doi.org/10.1111/j.1600-0404.1992.tb06032.x

26. Buschke H, Grober H. Free and Cued Selective Reminding with Immediate Recall (FCSRT+IR): FCSRT+IR Instructions for English and Spanish2.21.12. New York: Albert Einstein Collegeof Medicine; 2012.

27. Hübner LC, Loureiro F, Siqueira ECG, Tessaro, B., Smidarle, A., Quadros, TD et al. BALE: Bateria de Avaliação da Linguagem no Envelhecimento. In: Fonseca RP, Prando ML, Zimmermann N. Tarefas de avaliação neuropsicológica para adultos: memórias e linguagem. São Paulo: Memnon; (accepted, in preparation).

28. Chaves ML, Godinho CC, Porto CS, Mansur L, Carthery-Goulart MT, Yassuda MS et al. Doença de Alzheimer: avaliação cognitiva, comportamental e funcional. Dement Neuropsychol. 2011;5 Suppl 1:21-33.

29. Paddick SM, Gray WK, McGuire J, Richardson J, Dotchin C, Walker RW. Cognitive screening tools for identification of dementia in illiterate and low-educated older adults, a systematic review and meta-analysis. Int Psychogeriatr. 2017 Jun;29(6):897-929. https://doi.org/10.1017/S1041610216001976

30. Leite KS, Miotto EC, Nitrini R, Yassuda MS. Boston Naming Test (BNT) original, Brazilian adapted version and short forms: normative data for illiterate and low-educated older adults. Int Psychogeriatr. 2017 May;29(5):825-33. https://doi.org/10.1017/S1041610216001952 